\title{
Estimating Coal Strength Based on Historical Laboratory Tests and Geomechanics Classification
}

ISSN: 2578-0255

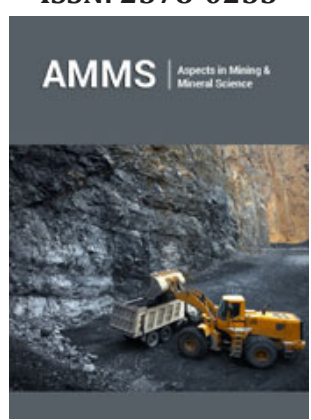

*Corresponding author: André C Zingano, Federal University of Rio Grande do Sul, Brazil

Submission: 監 August 06, 2020

Published: 址September 15, 2020

Volume 5 - Issue 4

How to cite this article: André C Zingano. Estimating Coal Strength Based on Historical Laboratory Tests and Geomechanics Classification. Aspects Min Miner Sci. 5(4). AMMS. 000618. 2020.

DOI: 10.31031/AMMS.2020.05.000618

Copyright@ André C Zingano, This article is distributed under the terms of the Creative Commons Attribution 4.0 International License, which permits unrestricted use and redistribution provided that the original author and source are credited.

\section{André C Zingano*}

Federal University of Rio Grande do Sul, Brazil

\begin{abstract}
The coal seam strength and the failure criteria that represents the behavior of the coal seam are very important for mine section and pillar design. In addition, the same to roof and floor layers, which will form the roof-pillar-floor system. Therefore, the rock mass characterization is the most important job and it is the beginning of the underground ground control design. Another issue is the distribution or behavior of the coal seam strength for the whole mine area. Sometime, the coal seam strength assumed the same for entire area, but it is not true because the coal seam is heterogenic and anisotropic, and also the coal strength gets some effects due to faults and spacing between fractures. This paper has the objective to demonstrate the use of themethodology for geomechanics characterization to determine the strength for the Bonito coal seam and discuss the coal seam strength distribution around the entire mine area. The intact coal strength considered the laboratory tests that were proceeded during the lasts 17 years, including triaxial and uniaxial strength tests. It was note that there is a strong correlation between all laboratory strength tests with $90 \%$ of interval confidence. The explanation for this coal seam strength variation is the presence of the discontinuities and their variation in quantity and quality at each location in the mine area because the coal seam rock classification and its behavior will be affected by the quantity and quality of fractures.
\end{abstract}

Keywords: Coal strength;Rock mass classification;Failure criteria

\section{Introduction}

The coal mining companies in Santa Catarina State apply the room-and-pillar mining method due to some features of the coal seam, like the shallow depth of the coal seam, but the reason is that subsidence is not allowed since 80's. There are two mineable coal seams: (i) Barro Branco and (ii) Bonito seam. Both seams are almost flat and cut by faults. The faults cause relative movement between blocks, which change the depth of the coal seam in each block. These tectonic forces also cause changes in the coal seam strength due to fractures and joints. The coal seam strength is very important for mine section and pillar design, and the failure criteria that represents the behavior of the coal seam. In addition, the same to roof and floor layers, which will form the roof-pillar-floor system. Therefore, the rock mass characterization is the most important job and it is the beginning of the underground ground control design. The coal seam geomechanics characterization takes into account the description the core from drilling in terms of RQD, quantity and quality of the discontinuity, and laboratory tests, mainly uniaxial and triaxial compressive strength for intact rock. Based on the geomechanics description, the rock mass classification can be applied using GSI, RMR and CMRR rock mass classification approaches for the coal seam, and roof and floor layers. After that, the failure criteria using Hoek and Brown approach was considered to determine the rock mass mechanics properties (friction, cohesion, and strength) for coal seam. Another issue is the distribution or behavior of the coal seam strength for the whole mine area. Sometime, the same coal seam strength is assumed for entire area, but it is not true because the coal seam is heterogenic and anisotropic, and also the coal strength gets some effects due to faults and spacing between fractures.

Despite the coal mining in Brazil exists since the beginning of the last century, some geomechanics characteristics still need some study, like the influence of the discontinuities on the coal seam strength. This paper has the objective to demonstrate the use of the methodology for geomechanics characterization to determine the strength for the Bonito coal seam and discuss the coal seam strength distribution around the entire mine area. In the almost last 20 years, a lot of geomechanics characterization for different proposes is 
done, but the main reason was to determine the coal strength and pillar design for both coal. Some of the effort to estimate the seam strength was in-situ tests and laboratory tests considering geomechanics characterization seams [1-3]. At the end of 90s, the Bonito coal seam began to be mined at the Treviso and Lauro Muller counties area, including the total five underground roomand-pillar mines. Many borehole samples from these mines were tested and geomechanics description done during these last years. Uniaxial and triaxial tests performed to complete the geomechanics description of the borehole samples, including quantity and quality of the discontinuities (spacing, RQD, and roughness). The coal seam strength was estimated (or calculated) using the Hoek-Brown failure criteria [4]. Those laboratory tests in different laboratories and in different test machines were made (both servo-controlled and non-servo-controlled devices). However, this could be a challenge or a problem when all the results of the tests had been together in a same database.

\section{Geomechanics Characterization}

The geomechanics characterization is the approach to estimate the rock mass strength, which consider the rock sample strength (uniaxial and triaxial strength), the description of the discontinuities in terms of quantity (spacing and RQD) and quality (mainly roughness). The geomechanics classification (RMR, CMRR and GSI) and finally the failure criteria by Hoek-Brown failure criteria [4] to determine the coal seam strength are applied. To obtain the parameters necessary to determine the RMR it is necessary to get the information of structural geology, water content and the strength of the rock. Laboratory tests (uniaxial and triaxial tests) estimate the strength of the rock but point load test could be used too.

\section{Geomechanics description}

The geomechanics description have done in fresh borehole cores. The interval analysis depend the objective, but normally assume 10-15m above (roof) and bellow (floor) the coal seam, and the coal seam itself. The description takes into account four parameters: (i) geology rock type, (ii) discontinuity spacing, RQD, and quality of the fracture. The discontinuity spacing and RQD are determined considering each geologic unit, for RQD only considering the core drilling peace above 4 inches, divided by the total length of the rock layer. The fracture spacing is the separation between fractures and it will represent the average spacing for the same rock layer. The quality of the fractures mainly represented by the roughness, but also the filling material and aperture (sometimes) could influence the shear strength of the discontinuity.

\section{Laboratory tests}

After the geomechanics description, some samples to prepare species for uniaxial and triaxial compressive strength are separated. The UCS will be one of the parameters of the RMR and CMRR. The uniaxial and triaxial compressive tests follow the standard proceeding from ASTM D 4543-85 and ASTM D 2664-95, respectively. Considering the high to diameter of 2-2.5 and diameter of $2 \mathrm{in}$. The faces of the species must be parallel and the load ratio during the test must be $1 \mathrm{MPa} / \mathrm{sec}$. Also, before the compressive tests, the sonic velocity can be determined (compressive and shear wave) to determine the dynamic elastic constants, considering the density of the rock. The UCS determine the compressive strength of the rock, and also determine the Young's modulus and Poisson's ration, it means the elastic parameters. The depth of the coal seam dictate the confinement pressure of the triaxial test. The maximum depth of the Bonito coal seam is from 60 to $350 \mathrm{~m}$, and then the confinement pressure $\left(\mathrm{s}_{3}\right)$ considered 2.5, 5.0 and 7.5MPa. The axial pressure $\left(s_{1}\right)$ is proportional to the confining pressure $\left(s_{1}=f\left(s_{3}\right)\right.$ ). The Mohr envelope estimates the values of cohesion (c) and friction angle $(\varphi)$ for intact rock (Equations 1, 2, and 3).

$$
\begin{gathered}
\tau=c+\sigma_{n} \tan \phi \\
\tau=\frac{1}{2}\left(\sigma_{1}-\sigma_{3}\right) \sin 2 \beta \\
\sigma_{n}=\frac{1}{2}\left(\sigma_{1}+\sigma_{3}\right)+\frac{1}{2}\left(\sigma_{1}-\sigma_{3}\right) \cos 2 \beta
\end{gathered}
$$

\section{Rock classification}

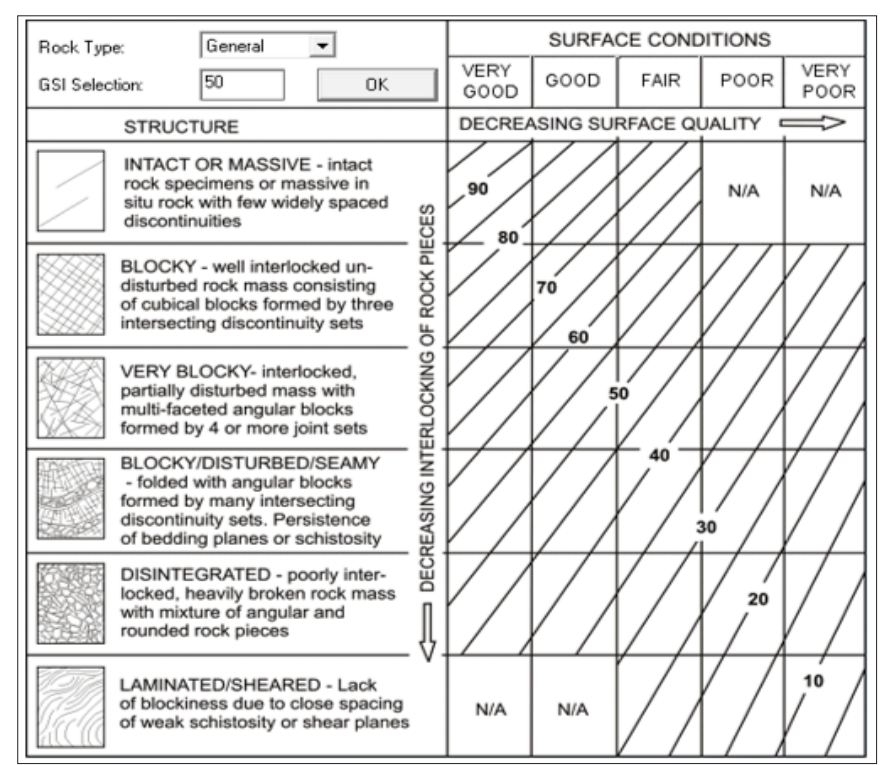

Figure 1: Table to determine GSI-Geological Strength Index.

Most of the rock mass classifications consider the following parameters: (i) quantity of the discontinuities, by RQD and fracture spacing; (ii) the quality of the discontinuities, mainly by roughness; (iii) rock strength; (iv) presence of water or sensitive of water; and (v) stress and relation between fracture orientation and orientation of the excavation. All of this information is collected from the geomechanics description of the borehole or and laboratory or field tests. The main propose of the rock classification is to determine the influence of the fractures on the rock mass strength and the scale reduction of the strength from intact rock to the rock mass. It means, the scale reduction of the rock strength considered to the Hoek- 
Brown failure criteria [4] to estimate the coal seam strength. The rock mass classification most used to coal seam characterization is the RMR-Rock Mass Ratio [5], followed by CMRR-Coal Mine Roof Rating [6]. The GSI-Geological Strength Index [4] considers the rock structure features and the quality of the discontinuities (Figure 1) but could be estimated by RMR minus five (RMR-5).

\section{Failure criteria}

The geomechanics behavior of the rock mass compared with the intact rock is different. The intact rock there not fractures or defect that could interfere on the strength and the laboratory tests are performed with intact rock. The rock mass got many different defects, like joints and bed bedding planes, which will cause the reduction of its strength [7]. The Hoek-Brown failure criteria for rock mass takes into account the rock mass classification to estimate the coal seam strength. Three main parameters are considered to apply the Hoek-Brown failure criteria: (i) intact rock strength $\left(\mathrm{s}_{\mathrm{ci}}\right)$; (ii) the rock constant mb; and (iii) the rock classification GSI-Geological Strength Index [8]. The Hoek-Brown failure criteria is the following equation (4), where s and a are constants related to the GSI.

$$
\sigma_{1}=\sigma_{3}+\sigma_{c i}\left(m_{b} * \frac{\sigma_{3}}{\sigma_{c i}}+s\right)^{a}
$$

For GSI<25:

$$
\begin{gathered}
S=0 \\
a=0.65-\frac{G S I}{200}
\end{gathered}
$$

For GSI>25:

$$
\begin{gathered}
s=\exp \left(\frac{G S I-100}{9}\right) \\
a=0.5
\end{gathered}
$$

The constant $\mathrm{mb}$ can be determined using the equation (9)

$$
m_{b}=m_{i} * \exp \left(\frac{G S I-100}{28}\right)
$$

The Heok-Brown failure criteria for intact rock is (Equation 10), where $\mathrm{mi}$ is the constant for intact rock, which could be determined based on the triaxial test, and $s=1$ and $a=0.5$

$$
\sigma_{1}=\sigma_{3}+\sigma_{c i}\left(m_{i} * \frac{\sigma_{3}}{\sigma_{c i}}+s\right)^{a}
$$

Therefore, the rock mass strength $\left(\mathrm{s}_{\mathrm{cm}}\right)$ can be determined using the equation (11) [9], considering the constants a, s, and mb based on the GSI classification (see equations above).

$$
\sigma_{c m}=\sigma_{c i} * \frac{\left[m_{b}+4 s-a\left(m_{b}-8 s\right)\right]\left(m_{b} / 4+s\right)^{a-1}}{2(1+a)(2+a)}
$$

\section{Estimating the Coal Seam Strength for Bonito Coal} Seam

The methodology proposed above has been used for geomechanics characterization since 1997. The geomechanics description and classification determined for many boreholes from five different mines located in the region that consider the Treviso and Lauro Muller Couties (Figure 2). The Table 1 shows the mines where the boreholes came from.

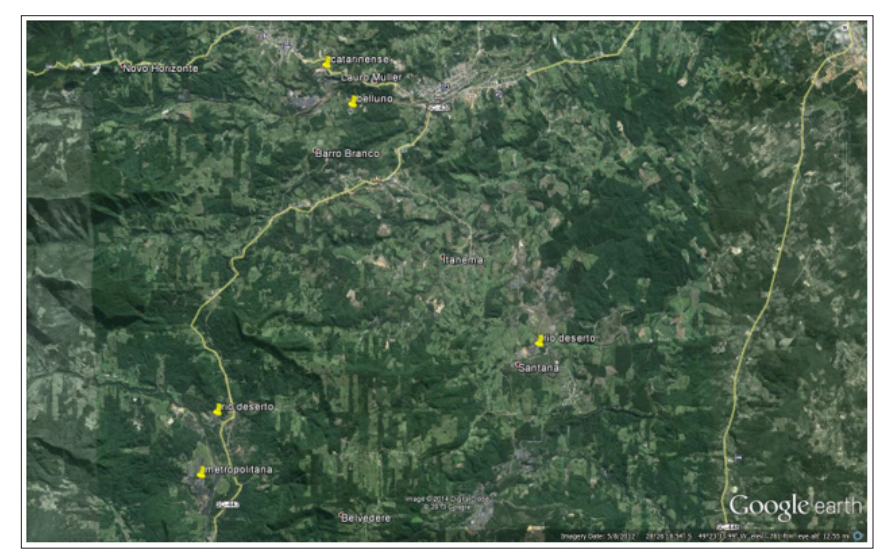

Figure 2: Location of the underground coal mines at the region of Treviso and Lauro Muller counties.

Table 1: Relation of the boreholes considered on this study.

\begin{tabular}{|c|c|c|}
\hline Zona & № de furos de sondagem & № de corpos de prova \\
\hline A & 1 & 10 \\
\hline B & 3 & 13 \\
\hline C & 2 & 6 \\
\hline D & 6 & 26 \\
\hline E & 3 & 17 \\
\hline Total & 15 & 72 \\
\hline
\end{tabular}

\section{Triaxial compressive test}

This study selected 72 triaxial compressive tests, which considered different confinement pressure (s3) and different compressive frame equipment. The objective was to joint together all these triaxial tests in a same database to study the behavior of the coal and estimate the uniaxial compressive strength. The Figure 3 shows the chart that correlates the confined pressure (s3) with axial pressure (s1). The lines represent the linear correlation of the data set, and interval of confidence $70 \%$. It can observe that there is good correlation considering the very large range of time of the borehole drilling and different location where the laboratory tests done. The chart of Figure 1 shows the confidence of interval of $70 \%$, and the coefficient of correlation is 0.7 , this is because the dispersion of the results for each confinement pressure [10-12]. The variation of the axial pressure (s1) is due the heterogeneity and anisotropy of the coal seam in the area in study. Therefore, there is a strong correlation about compressive strength. The average 
uniaxial compressive strength for the coal of the Bonito seam is $32.4 \mathrm{MPa}$, considering only the triaxial tests. The dispersion of the results for each confinement pressure is also observed for uniaxial compressive test. Figure 4 shows the histogram for 15 uniaxial compressive test for the Bonito coal seam. The uniaxial compressive strength represents the average UCS for each borehole. The total average compressive strength based on the uniaxial compressive tests is $30.9 \mathrm{MPa}$, pretty close to the strength estimated from the triaxial test. The standard deviation is $8.41 \mathrm{MPa}$, and the maximum and minimum values are 20 and $40 \mathrm{Mpa}$, respectively.

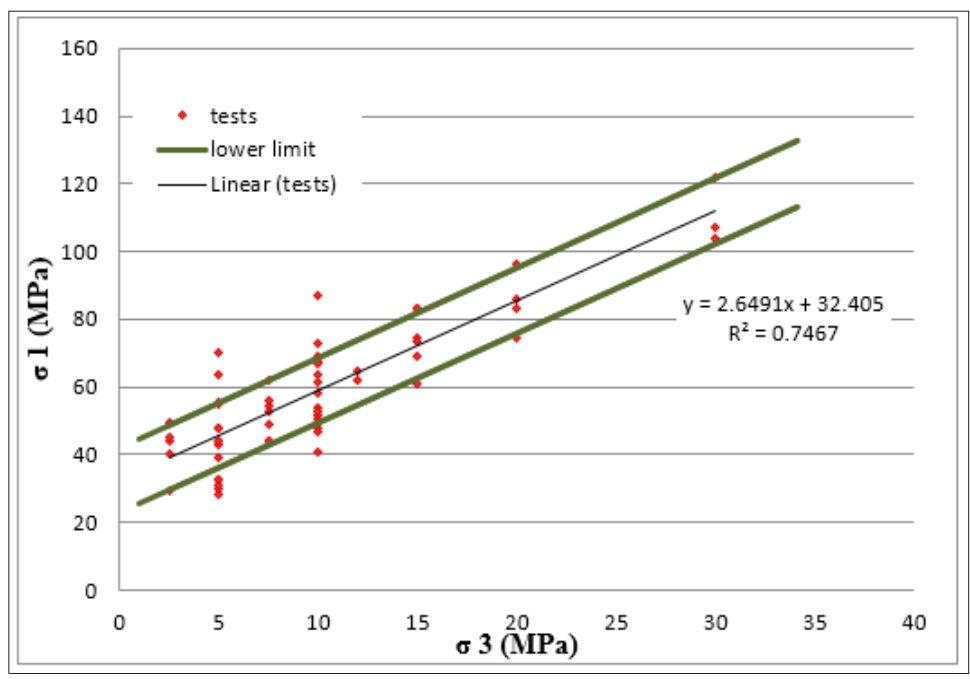

Figure 3: Correlation chart for s3 and s1, including the interval of confidence of $70 \%$.

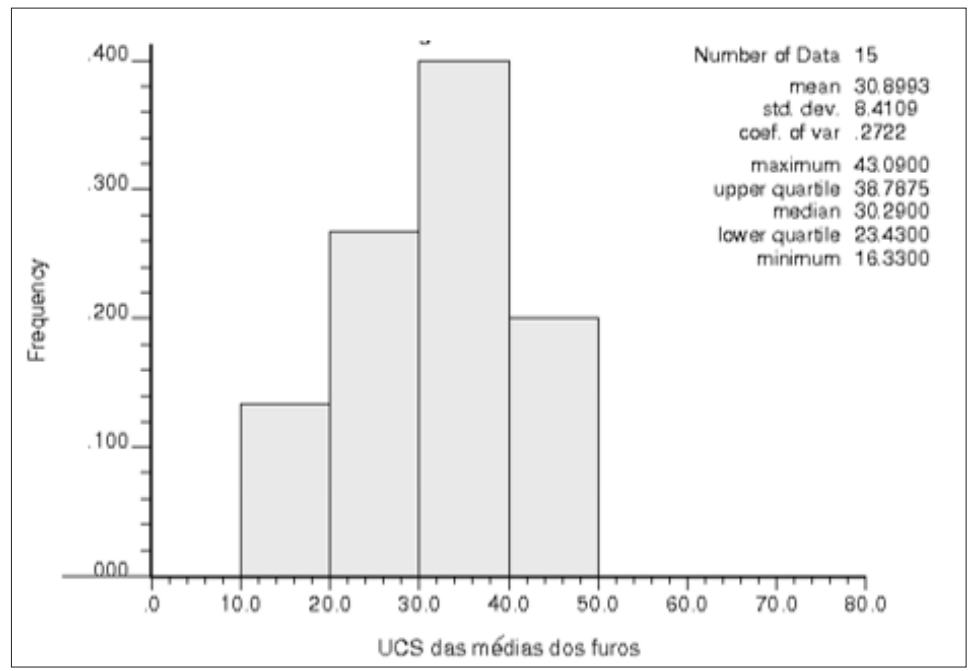

Figure 4: Histogram of frequency of the uniaxial compressive strength test for the Bonito coal seam.

\section{Rock classification and coal strength}

The results of compressive strength tests (triaxial and uniaxial tests) show a good correlation for the whole area in study. The question is that the coal seam strength could not have the same behavior, because the presence of the discontinuities. Then, the GSI classification correlated with the uniaxial strength for each borehole to try to understand and check if there is some relation between the UCS and coal seam strength with the GSI classification. The RMR and GSI classification methods take into account the quality and quantity of the discontinuities, at the cores of the boreholes. Table 2 shows the GSI classification for the 15 samples that considered for uniaxial compressive tests.
Table 2 shows the GSI for intact rock, and GSI for the rock mass for each borehole. The coal seam strength for each borehole related to the GSI classification as shown at Table 2. The GSI for intact rock assumed the value 100 , because the intact rock there is no discontinuity. Therefore, the average strength for intact rock was calculated and the Hoek-Brown failure criteria calculated the strength for intact coal. Once applied the GSI rate for rock mass, the coal seam strength reduced because the presence of the discontinuities and bedding planes. In this case, the GSI had calculated based on the RMR classification (RMR-5) for each borehole, and then the coal seam strength calculated. Figure 5 shows the strength of the coal rock and for the Bonito coal seam related 
to the GSI. It can be observed that there is a strong correlation between the strength for coal and seam and the GSI. This is because the influence of the quantity and quality of the discontinuities considered on the rock mechanics classification RMR and GSI. The Bonito coal seam is very fractured, then the coal seam drop very high from 30.9MPa to less than 7MPa. The data of this study got the behavior very close or similar to the studies that determined the range of the Bonito coal seam strength [13-15]. The average Bonito coal seam strength, considering the borehole analysis of this study is $4.19 \mathrm{MPa}$, and the maximum and minimum values are 6.68 and 1.69MPa, respectively. Zingano [2] made a very extensive structure survey to determine the influence of the discontinuities on the coal seam strength and conclude that the less coal seam strength is $4.06 \mathrm{MPa}$, and Gonzatti [1] estimated the coal seam strength between 4.08 and 5.7 MPa. Both considered the Hoek-Brown failure criteria. The map on Figure 6 shows the anisotropy of the coal seam strength. This anisotropy could be explained by the proximity of faults and other regional structures. Therefore, it is important to calculate or estimate the coal seam strength, but it is necessary to correlate with the structural map of the mining area to check the influence of faults on the coal seam strength.

Table 2: GSI classification of the coal seam compared with the uniaxial strength and coal seam strength.

\begin{tabular}{|c|c|c|c|c|c|c|}
\hline \multirow{2}{*}{ Mine } & \multirow{2}{*}{ Borehole } & \multirow{2}{*}{ UCS (MPa) } & \multicolumn{2}{|c|}{ Intact Rock } & \multicolumn{2}{|c|}{ Rock Mass } \\
\hline & & & GSI & Strength (MPa) & GSI & Strength (MPa) \\
\hline A & 1 & 40.74 & 100 & 37.79 & 33 & 3.72 \\
\hline \multirow{3}{*}{ B } & 2 & 30.29 & 100 & 28.09 & 49 & 4.07 \\
\hline & 3 & 23.43 & 100 & 21.73 & 35 & 2.25 \\
\hline & 4 & 38.85 & 100 & 36.04 & 43 & 4.53 \\
\hline \multirow{2}{*}{$\mathrm{C}$} & 5 & 43.09 & 100 & 39.97 & 55 & 6.68 \\
\hline & 6 & 36.80 & 100 & 34.14 & 55 & 5.71 \\
\hline \multirow{6}{*}{$\mathrm{D}$} & 7 & 16.33 & 100 & 15.14 & 38 & 1.69 \\
\hline & 8 & 23.14 & 100 & 21.46 & 47 & 2.70 \\
\hline & 9 & 42.21 & 100 & 39.15 & 55 & 6.54 \\
\hline & 10 & 25.84 & 100 & 23.97 & 48 & 3.39 \\
\hline & 11 & 30.50 & 100 & 28.29 & 49 & 4.10 \\
\hline & 12 & 19.95 & 100 & 18.51 & 35 & 1.92 \\
\hline \multirow{3}{*}{$\mathrm{E}$} & 13 & 30.29 & 100 & 27.09 & 57 & 4.76 \\
\hline & 14 & 23.43 & 100 & 24.01 & 59 & 4.44 \\
\hline & 15 & 38.60 & 100 & 35.81 & 57 & 6.29 \\
\hline \multicolumn{2}{|c|}{ Average } & 30.90 & & 28.75 & & 4.19 \\
\hline
\end{tabular}

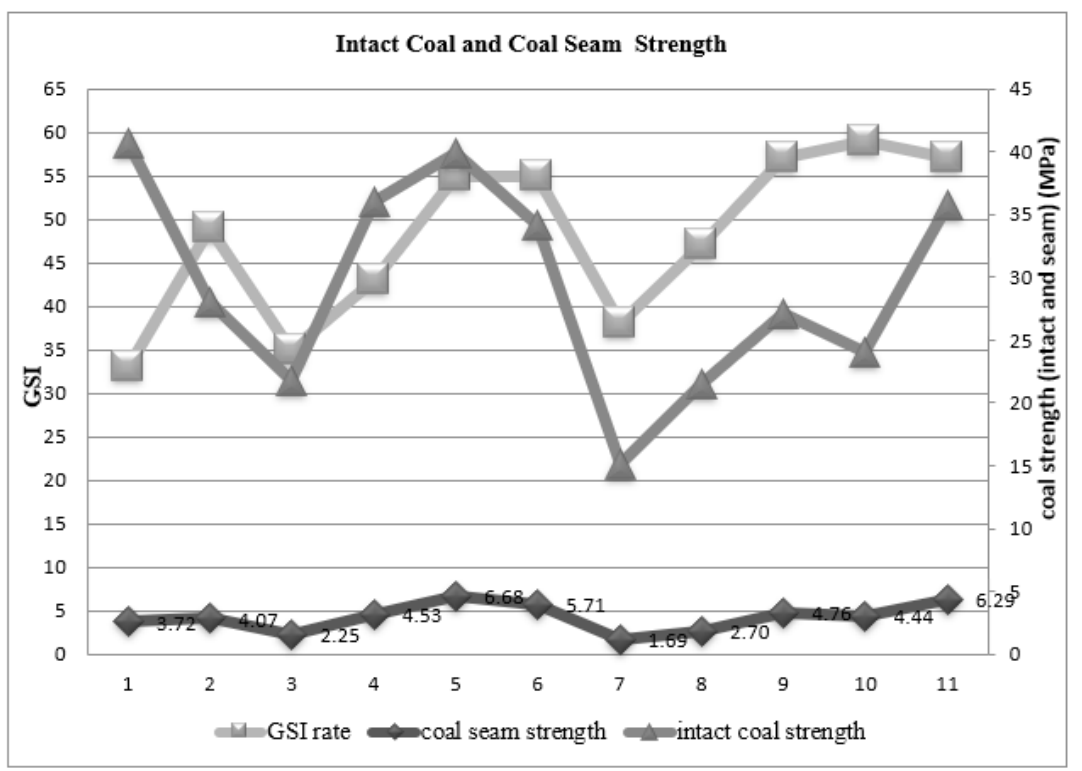

Figure 5: Intact coal and coal seam strength related to GSI. 


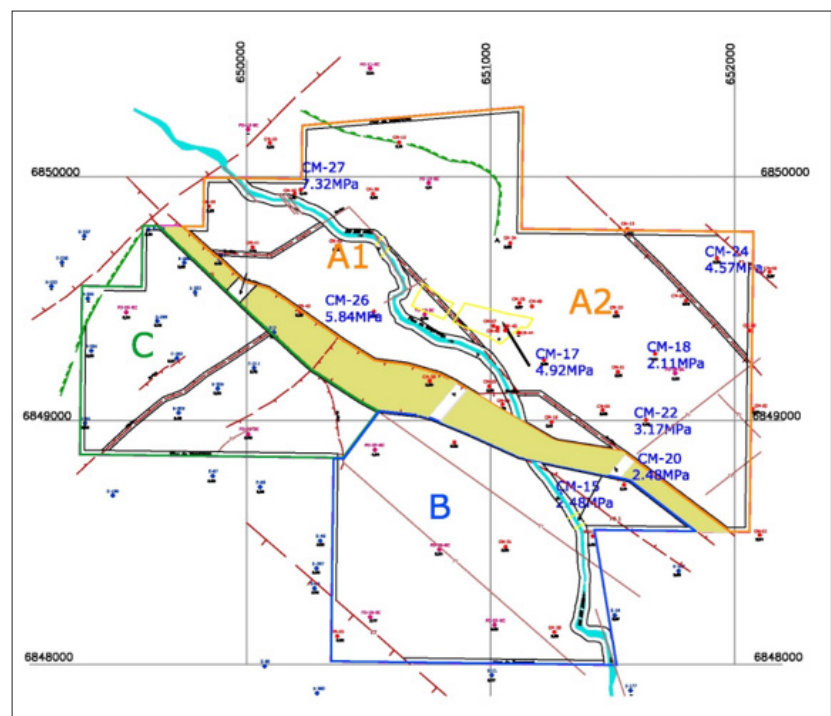

Figure 6: Map the mining area that shows the location of the boreholes with the respectively coal seam strength, and the position of faults.

\section{Conclusion}

The strength of the intact coal has uniform behavior for the whole region considered on this study. However, the coal seam strength has more anisotropy due to variation of quantity and quality the discontinuities, mainly when the borehole is close to faults. Therefore, the study demonstrated the importance of the coal seam geomechanics characterization. Only the coal intact strength determination is not enough to estimate the seam strength. It is necessary to determine the quantity and quality of the fractures. The Bonito coal seam got another step of the understanding its behavior, and this behavior could be incorporated to the pillar design.

\section{References}

1. Gonzatti C (2007) Proposal for the estimation of the in-situ uniaxial compression strength of coal layers using geophysics. USP-São Carlos, Brazil.

2. Zingano AZ (2002) Geo mechanical modeling for the design of coal pillars. PPGEM-UFRGS, Brazil.

3. Zingano A, Stein M, Karas R (2010) Estimation of the mechanical behavior of the layers that form the floor-layer-ceiling system in coal mines. VI Brazilian Congress of Underground Mine and VI Brazilian Congress of Open Sky Mine - IBRAM, Belo Horizonte, Brazil.

4. Hoek E, Brown ET (1997) Practical estimates of rock mass straight. Int ] Rock Mech and Min Sci 34(8): 1165-1186.
5. Bieniawski ZT (1973) Engineering classification of jointed rock masses. Trans S Afr Inst Civ Engrs 15(12): 335-344.

6. Hoek E (1994) Strength of rock and rock masses. ISRM New Journal 2(2): 4-16.

7. Bieniawski ZT (1976) Rock mass classifications in rock engineering. In: Bieniawski ZT (Ed.), Exploration for Rock Engineering. Cape Town, South Africa. pp. 97-106.

8. Hoek E, Kaiser PK, Bawden WF (1995) Support of underground excavation in hard rock. Rotterdam, Netherlands, p. 215.

9. Hoek E, Brown ET (2002) Failure criterion. Consulting Engineer, Vancouver, Canada. Carlos Carranza-Torres, Itasca Consulting Group Inc., Minneapolis, USA and Brent Corkum, Rocscience Inc., Toronto, Canada.

10. Bieniawski ZT (1974) Estimating the strength of rock materials. J S Afr Inst Min Metall 74(8): 312-320.

11. Brady BHG, Brown ET (1985) Rock mechanics for underground mining George Allen and Unwin Editora, London.

12. Hoek E, Kaiser PK, Bawden WF (1998) Support of underground excavation in hard rock. Netherlands, p. 215.

13. ASTM D4543-85 (2019) Standard practices for preparing rock core as cylindrical test specimens and verifying conformance to dimensional and shape tolerances, USA.

14. ASTM D3148-02 Standard test method for elastic moduli of intact rock core specimens in uniaxial compression. USA.

15. ASTM D2664-04 Standard test method for triaxial compressive strength of undrained rock core specimens without pore pressure measurements. USA

For possible submissions Click below: 